vol. $37-n^{\circ} 1$ et 2 | 2021

Travail et migrations

\title{
Ochandiano (de) Jean-Luc, Lyon à l'italienne
}

Jordan Pinel

\section{OpenEdition}

Journals

Édition électronique

URL : https://journals.openedition.org/remi/18754

DOI : 10.4000/remi. 18754

ISSN : $1777-5418$

Éditeur

Université de Poitiers

Édition imprimée

Pagination : 319-321

ISBN : 979-10-90426-69-6

ISSN : 0765-0752

Référence électronique

Jordan Pinel, «Ochandiano (de) Jean-Luc, Lyon à l'italienne », Revue européenne des migrations

internationales [En ligne], vol. 37 - $\mathrm{n}^{\circ} 1$ et 2 | 2021, mis en ligne le 25 novembre 2021, consulté le 17 mai 2022. URL : http://journals.openedition.org/remi/18754 ; DOI : https://doi.org/10.4000/remi.18754

Ce document a été généré automatiquement le 17 mai 2022.

(c) Université de Poitiers 


\title{
Ochandiano (de) Jean-Luc, Lyon à l'italienne
}

\author{
Jordan Pinel
}

\section{RÉFÉRENCE}

Ochandiano (de), Jean-Luc, Lyon à l'italienne. - Lyon : Éditions Lieux Dits, 2016. - 272 p.

ISBN : 978-2-36219-076-6

1 C'est un long et minutieux travail de mémoire que nous propose Jean-Luc de Ochandiano, conservateur des bibliothèques à l'Université Jean Moulin Lyon III. Près de cinq ans d'analyses d'archives publiques ou privées ont été nécessaires pour retracer deux siècles de présence italienne dans la région lyonnaise. C'est notamment à partir de papiers d'identités et surtout de photographies conservées par des familles d'origine italienne que l'auteur rend compte de cette présence de longue date. Tous les éléments qu'il a récoltés témoignent aujourd'hui d'une histoire migratoire collective faite de multiples histoires individuelles et familiales.

2 L'originalité du travail d'historien qui a conduit à cet ouvrage est de lier l'histoire migratoire italienne à la ville de Lyon et son évolution d'un point de vue historique, géographique et urbanistique. Cela conduit à se plonger dans l'histoire industrielle et la naissance des quartiers ouvriers, marqués par l'immigration, qui poussent l'auteur à élargir son horizon au-delà de Lyon pour s'intéresser à sa banlieue ouvrière: Villeurbanne, Vénissieux, Saint-Priest ou encore Vaulx-en-Velin.

3 Trois parties composent l'ouvrage, qui suit une logique chronologique épousant les grandes étapes d'installation des Italiens à Lyon, et plus largement en France. Même si l'on peut regretter le manque d'homogénéité dans leur calibre - de 120 pages pour le premier à cinquante pages pour le dernier - ces chapitres permettent de percevoir très clairement les différentes phases d'installation de la communauté italienne à Lyon et plus largement en France. 
4 La première, "L'origine du mouvement ", débute en 1815 à partir de la chute de l'Empire napoléonien et s'achève à la veille de la Première Guerre mondiale. Ce chapitre retrace les migrations en provenance des différents royaumes qui composent l'Italie jusqu'à son unification en 1861 - composées à la fois d'une paysannerie venant en France depuis le Piémont pour compléter ses revenus par l'artisanat (maçonnerie, menuiserie, tissage) qu'elle propose une partie de l'année, ainsi que d'une élite aristocratique et bourgeoise, politisée et soucieuse d'unifier l'Italie. Puis la présence italienne devient plus ouvrière, portée par l'ensemble des grands chantiers lyonnais du Second Empire. La migration italienne s'intensifie jusqu'à faire émerger ce que l'auteur décrit - mais ne dénomme pas - comme les prémices d'un champ migratoire. En 1881, plus de 10000 Italiens sont recensés à Lyon par les autorités, plus de 12000 en 1911. Audelà des chiffres et du contexte historique, l'auteur s'attarde surtout à décrire les conditions de vie de cette communauté italienne : de la création d'un artisanat et d'un savoir-faire dont bénéficie la ville - autour de la menuiserie, de la plâtrerie, du tissage ou de la mosaïque - aux différents lieux de vie de ces immigrés permettant ainsi de percevoir une géographie historique de Lyon au prisme de la population italienne. L'auteur évoque également la xénophobie importante et galopante dont cette population est victime.

5 La seconde partie, "D'une guerre à l'autre ", retrace les conséquences de la Première Guerre mondiale et des difficiles relations franco-italiennes sur les Italiens de Lyon. Jean-Luc de Ochandiano montre la mobilisation politique et industrielle de cette communauté dès 1914, puis l'essor qu'a connu l'immigration italienne après la Grande Guerre, dû au fort besoin de main-d'œuvre face à l'industrialisation importante ainsi qu'à l'afflux d'exilés politiques après l'accession au pouvoir de Benito Mussolini en 1922. Cet afflux important est constaté par l'auteur à travers les conditions précaires et insalubres de logement, en particulier avec l'exemple des «baraques » et notamment celles de Gerland où les ouvriers dans le secteur de la chimie, verrerie ou métallurgie, se logent dans des conditions désastreuses, tout en espérant que les crues à répétition du Rhône n'emporteront pas leurs abris. Face à cette précarité, l'auteur rappelle la création de nombreuses œuvres catholiques de charité promues par la bourgeoisie locale pour venir en aide à cette population. De nombreux dispensaires permettent ainsi de donner les premiers soins aux populations les plus pauvres, et des patronages permettent d'organiser des Noëls solidaires et d'envoyer les enfants en colonies de vacances. Dans ce cadre, le témoignage d'une Italienne, enfant dans les années 1930, permet de rendre le récit de l'auteur vivant et d'illustrer par le propos une histoire encore récente.

6 Enfin, la troisième et dernière partie, "Le temps de l'intégration et de la mémoire " débute en 1940 et retrace l'effet de la Seconde Guerre mondiale sur les Italiens à Lyon et en France de manière plus large. La défiance de nombreux Français, menant à des actes xénophobes, est alimentée par l'entrée en guerre de l'Italie fasciste de Mussolini aux côtés de l'Allemagne nazie d'Hitler. De nombreux Italiens en France perdent alors leurs emplois et subissent de nombreuses violences, dont l'auteur a retrouvé trace dans les archives. Cette partie, peut-être trop courte, se clôt en rappelant la présence de nombreux Italiens - tel Titta Coïs, franc-tireur partisan fusillé par les Allemands en août 1944 - dans la résistance. Puis, le chapitre accélère la narration pour rappeler la forte présence de l'immigration italienne au cours des Trente Glorieuses, où Lyon demeure un des hauts lieux français de l'installation italienne où se retrouvent les 
anciennes filières migratoires du nord de l'Italie, les nouvelles provenant du Sud. Cette histoire récente prend géographiquement place dans les quartiers à forte présence immigrée - Croix-Rousse ou Gerland - et dans les banlieues lyonnaises. À partir de cette forte migration d'après-guerre, l'auteur insiste sur le processus d'intégration des Italiens en France, notamment au travers des évolutions socioprofessionnelles au sein de la communauté et de l'école, qui a agi sur la promotion sociale des secondes générations.

7 L'auteur conclut sur les enjeux de mémoire de cette présence italienne à Lyon, dans le département du Rhône et en France. L'effort du travail historique indéniable de cet ouvrage met en avant de nombreux « souvenirs » italiens en France. Et l'ensemble des photographies mises en avant de manière importante à chacune des pages du livre permet de rendre "vivante" cette histoire collective et de faire le lien entre une mémoire collective et des mémoires familiales. Le migrant italien, qu'il soit épicier, ouvrier ou sculpteur, a marqué l'évolution de la ville, laissé une empreinte culturelle, mais aussi politique et syndicale forte dans le paysage lyonnais. Ainsi, plusieurs histoires de vie viennent témoigner de cet enracinement local progressif des Italiens, à l'instar de Madeleine Alloisio, syndicaliste CGT avec son époux, devenue adjointe au maire de Saint-Priest. L'auteur réussit donc à nous montrer l'intérêt d'observer l'agglomération lyonnaise au prisme de la présence italienne. Deux siècles d'histoire italienne dans la capitale des Gaules qui montrent un lien fort entre l'Italie et Lyon, tout comme entre les Italiens et la France.

\section{AUTEURS}

JORDAN PINEL

Docteur en géographie

CNAV/MIGRINTER 